\title{
ON LEXICALLY BIASED DISCOURSE ORGANIZATION IN TEXT GENERATION
}

\author{
Leo Wanner \\ University of Stutigart \\ Keplerstr.17, 70174 Stuttgart, Germany
}

\section{Summary}

In this paper, we show that Reiteration and Collocalion relations as introduced by Italliday and Hasan may function as lexically biased discourse structure relations and that these relations are well represented by sequences of Mel'čuk's Lexical Functions.s (t.rs). We propose to use LF sequences for the final determinittion and realization of discourse organization during lexical choice in text generation.

\section{LEXICAL PHENOMENA IN DIS- COURSE}

\subsection{The Problem}

In text generation, the task of content selection and discourse organization, i.e. text plamning, hats often been opposed to the task of linguistic realization of the information selected and organized by the text planning process (cf., e.g., McKeown and Swartout, 1987). Ilowever, discourse organization is not possible witltout taking into account linguistic means that are available to express a particular meaning (cl., e.g., Metcer, 1992; Rubinoff, 1992). lispecially the failure to integrate lexical clioice into the planning process may lead to monotonous, awkward, or even ungranmatical text (note that, when used separately, the chases in ( $1 a)$ and (2a) are fully acceptable): ${ }^{1}$

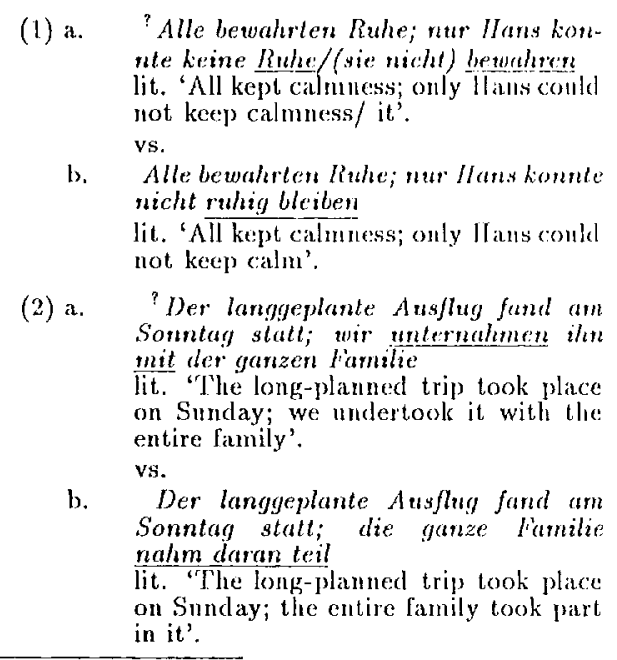

\footnotetext{
${ }^{1}$ In the following examples, the inappropriate le xical expres sion in the (a) sentences and its more appropriate alternative in the (b) sentences are underlined.
}

\author{
(3) a. *Hans machte cinc Lintdeckung; diese \\ linldeckung war wirklich \\ lit. 'Ilans made a discovery; this dis- \\ covery was real'. \\ vs. \\ b. Ilans machte cine Entdeckung; diese \\ lintleckinng war einc lintdechiung im \\ wothsten Sinne des Wortes \\ lit. "Ilans made: at discovery; this dis- \\ covery was a discovery in the real sense \\ of the word'.
}

These examples slow that lexical constraints are of a special relevance to discourse organization if related discourse serments communicate information on the same or related object, event, process, etc. While in the past, considerable work has been done on the realization of anaphoric links between related entities via referring expressions (cf., e.g., Tutin and Kittredge, 1992; Dale, 1989; Reiter, 1991), only a few proposals cmphasize the relevance of lexical means for the realizalion of discourse structure relittions such ass CONTRAS'T in (1b) and ERABORATION in (2b) and (3b). ${ }^{2}$ It is important to note that the actual realization of a discourse relation may vary with the semantics of the lexemes involved. For exanple, in (4), the second clause is an IN'TRRPIRETATION or CONSIRUJENCE of the first; despite the analogous syntactic construction in (5), the second clanse is a JustrFICATION or an EXPLANA'TION of the first rather than an IN'TiRPRETATron or CONSEQUENCl:
(4) Ite travels a lot - he is a 'professional' trameller.
(5) He flics a lot -... he is a mofessional fiees.

\subsection{The Proposal}

Such relations as those between Ruhe bewahren '[to] kecp calmness' and ruhig bleiben '[to] keep calm' (in 1); between Aus/lug findel slall 'trip takes place' and am A rsfluy teilnehmen. '[to] take part in the trip' (in 2); and between eine lintdeckung 'discovery' and im walirsten Sinne des Wortes 'in the real sense of the word' (in 3) have been introduced by (Ifalliday and II asau, 1976) as Reiteration and Collocation relations. ${ }^{3}$

\footnotetext{
${ }^{2}$ In this paper, we use the nanes of tiscourse structure relittions as they are known from the Rhetorical Structure Theory (Mann and 'Thompson, 1987).

${ }^{3}$ Although preferably usted so far to descrilue discourse links between information segments realized by noms, Reiteration and Collocation relations may well hold between segments which are realized by other parts of speech and even by multiple word expressions.
} 
Reiteration stands for a strict repetition of a lexical expression in related discourse segments; for a substitution of a lexical expression by a synonym, or for a substitution by a superordinate. Consider the following examples, which illustrate the three different reiteration relations (strict repetition in (7a), synonymy in (7b), and superordination in (7c)):

(6) Last summer, Monica flew to Italy,

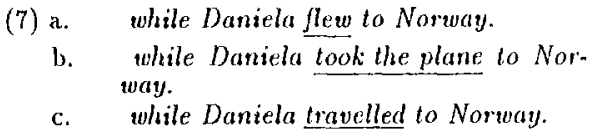

Further substitution relations such as metaphoric repetition (7d), negated antonymy (7e), etc. can be added:

(7) d. while Danicla wafted away to Norway.

e. Daniela also did not stay at home.

Collocation stands for 'any recognizable lexicosemantic relation' between lexical expressions in related discourse segments. Examples of collocation relations are attribution (7f), partition (7g), means (7h), etc.:

$$
\begin{aligned}
& \text { (7) f. it was a very pleasant journcy. } \\
& \text { g. making a stop over in Murich. } \\
& \text { l. } \quad \text { it was one of those big aircrafts. }
\end{aligned}
$$

As our examples show, reiteration and collocation relations help to ensure not only cohesion, but also coherence in texts. Therefore, a text generator las to provide an organization of lexical resources that tailors discourse structure relations to reiteration and collocation relations. This presupposes, on the one hand, a precise picture of which reiteration and collocation relations are available in language and how they are realizable; and, on the other hand, a fine-grained discourse model that contains these relations.

To make allowance for the global discourse organization, which is performed independently from lexical resources, we suggest a two level text planning task implementation, with the first level realized by a Rhetorical Structure Theory (Rs'T) (Mann and 'Thompson, 1987) style text planner and the second level --by a separate lexical choice module. Then, the discourse organization of a text is done in two steps: in the first step, the text planner predetermines the discourse structure relations; in the second step, the lexical choice module provides, in accordance with linguistic constraints, the final determination and the realization of these discourse structure relations.

The present paper reports an attempt to define lexically biased discourse structure relations used in a partially implemented lexical choice module. Due to the lack of space, we do not discuss the module itself; it is described in detail in (Wanner, 1992, 1994). Ilere, we demonstrate how discourse organization for text generation can be refined by lexically biased discourse structure relations and how these relations are related to global discourse relations specified in the output of an RST style text planner.
In contrast to the most discourse models (cf., e.g., McKeown, 1985; Grosz and Sidner, 1986; Mann and Thompson, 1987), which take the clause as the minimal discourse segment, we consider as discourse segments "perspectives" (cf. McCoy, 1989) - specific views taken on a semantic entity (an object, an event, etc.). A perspective is a wording which is tailored to the lexical repertoire of an entity; it is realizable as a clanse, a phrase, or as a single lexeme. Fach of the clauses in the examples above can be considered as a realization of a single perspective; and the reiteration and collocation relations that hold between the clauses - as well-defined perspective pairs.

In our model, a single perspective is represented as a composition of Mel'culk's Lexical Functions (hereafter Llis) (Mel'čuk and Polguère, 1987); perspective pairs are represented as $\mathrm{LF}$ secuences.

The following distinctive features characterize our model:

- it makes sure that all relations defined are expressible in language,

- it allows for a realization of lexical relations as subclansal relations between discourse segments,

- it is sensitive to lexical and syntactic variations for the realization of discourse structure relations.

\section{LEXICAL FUNCTIONS IN DIS- COURSE}

\subsection{The Basics}

Formally speaking, an $\mathrm{LF} f$ is a standard semanticolexical relation which holds between a lexeme $h_{1}$ (the

\begin{tabular}{|c|c|}
\hline Syn: 'synonym' & $\operatorname{Syn}($ bible $)=$ God's Book \\
\hline Anti: 'antonym' & Anti (victory $)=$ defeat \\
\hline Gener: 'liyperonym' & Genor $($ lamb $)=$ meat \\
\hline Figur: 'metaph. rep.' & Figur $(f \circ g)=$ wall $[\circ f(\% l]$ \\
\hline Conv 21 : 'conversion' & $\begin{array}{l}\text { Conv } 21 \text { (lo include) } \\
=[10] \text { belong }\end{array}$ \\
\hline$S_{0:}$ 'siluation' & $S_{0}($ to leach $)=$ teaching \\
\hline $\mathrm{S}_{1}$ : 'actor' & $\mathrm{S}_{3}($ lic $)=\operatorname{litir}$ \\
\hline$\Lambda_{0}$ : 'situational adj.' & $A_{0}(s u n)=$ solur \\
\hline$V_{0}:$ 'action' & $\mathrm{V}_{0}($ deal $)=[$ to $]$ deal \\
\hline Magn: 'intense(ly)' & $\begin{array}{l}\operatorname{Magn}(\text { beauty })=\text { real, } \\
\text { sturning }\end{array}$ \\
\hline Oper, : 'perform' & $\begin{array}{l}\text { Oper }_{1}(c r y) \\
=\left[\text { to } \text { let oul }_{(a \mathrm{cos} y)}\right.\end{array}$ \\
\hline Incep: 'begimning' & $\begin{array}{l}\text { Incep }(\text { to sleep }) \\
=[\text { to }] \text { fall asleep }\end{array}$ \\
\hline Fin: 'cnd' & Fin $($ to sleep $)=[$ to $]$ wake $n p$ \\
\hline Caus: 'causation' & $\begin{array}{l}\text { Cans(to sleep) } \\
=[t o] p u t \text { to sleep }\end{array}$ \\
\hline Manif: 'manifestation' & $\begin{array}{l}\text { Munif(happy) } \\
=[\text { lo] beam uilh joy }\end{array}$ \\
\hline
\end{tabular}
keyword of $f$ ) and a set of lexemes $f(t)$ (the value of f). Examples of uFs are:

Mel'čuk distinguishes about sixty simple LFs of the above kind. Simple t,rs can further be combined with 


\begin{tabular}{|c|c|}
\hline Oper $_{1} \wedge$ Oper $_{1}$ & $\begin{array}{l}\text { strict repetition }([t o] \text { have } \\
\text { a look } \wedge[\text { to] have a look) }\end{array}$ \\
\hline$V_{0} \wedge S_{y} n V_{0}$ & $\begin{array}{l}\text { synonymy } \\
([\text { to }] \text { discippear } \wedge[\text { to }] \text { vanish })\end{array}$ \\
\hline$V_{0} \wedge$ Geners $_{0}$ & $\begin{array}{l}\text { superordination } \\
([\text { to }] \text { search }(\text { a flat }) \wedge \text { reprisal })\end{array}$ \\
\hline$S_{0} \wedge$ ligurs & $\begin{array}{l}\text { metaph. repetition } \\
(f \circ g \wedge \text { wall of } f \circ g)\end{array}$ \\
\hline$V_{0} \wedge$ NoT $\wedge$ nti $V_{0}$ & $\begin{array}{l}\text { neg. antonymy } \\
(\text { close } \wedge \text { not far }(n w a y)\end{array}$ \\
\hline$V_{0} \wedge$ Conv $_{21} V_{0}$ & conversion $([l 0] \operatorname{sell} \wedge[10]$ buy $)$ \\
\hline$V_{0} \wedge S_{1}$ & process-actor $([l o]$ lie $\wedge$ liar $)$ \\
\hline Caus $\wedge V_{0}$ & $\begin{array}{l}\text { cause-process } \\
([t o] \text { put to slecp } \wedge[\text { to }] \text { slcep })\end{array}$ \\
\hline Incep $\wedge V_{0}$ & $\begin{array}{l}\text { initialization-process }([t o] \\
\text { fall asleep } \wedge[10] \text { slecp }\end{array}$ \\
\hline$\Lambda_{0} \wedge$ Magn o $S_{0}$ & $\begin{array}{l}\text { attribution (beauliful } \wedge \\
\text { real beauly) }\end{array}$ \\
\hline$V_{0} \wedge$ Manif & $\begin{array}{l}\text { manifestation ([to] be happy } \wedge \\
{[\text { to] beam wilh joy) }}\end{array}$ \\
\hline
\end{tabular}

'Table 1: The realization of reiteration and collocation relations by tol sequences

each other; the meaning of such compler Le's is, as a rule, a combination of the meanings of the participating r.Fs. 'T'hus, AntiMagn means 'slightly' (c.g., AntiMagn(injury) $=$ minor); and Incepoper 'stant performing' (e.g., Incep Oper ${ }_{1}($ debate $)=[$ lo] start $(a$ (lebate)). ${ }^{4}$

In text generation, the benefits from lis are theefold: (i) they provide subclatusal collocational constraints between the keywords and the values (cf. lor(lanskaja et al, 1991) as, e.g., between narrou and majority (with AntiMagn(majority) $=$ narrow) in I/oudini won with a narrow majority; (ii) they provide interclausal cooccurrence links (cf. 'I'utin and Kittredge, 1992 ) between the keywords and the values as, e.g., between spaghetli and pusta (with Gener(spaghelli) = pasta) in Let's take spaghelli; pasta is not bad here; and (iii) they allow for explicit statements on the cooccurrence between values of various lws in related discourse segments, as, e.g., between the values of $V_{0}($ slecp $)=$ [lo] sleep and Incep(sleep $)=[$ lo] sink inlo sleep in llardly in bed, 'Tony sank into slecp and slept all the night till the morning.

In our work, we use (i) for single perspective realizalions (ce. Wanner and Batemnan, 1990); (ii) and (iii) serve for the representation of perspective sequences, i.e, roiteration and collocation relations in discourse. One such relation is given by all pairs LF' $\wedge \mathrm{LF}_{2}$ ('LF sequences') which show the same cooccurrence behavior (c.g., the sequences Oper $1 \wedge$ Oper $_{1}$ and $V_{0} \wedge V_{0}$ show the same cooccurrence behavior; both stand for strict repetition). Consider Table 1.

LF sequences are directed, i.e. $L_{1} \wedge L_{2} \neq H_{2} \wedge$

\footnotetext{
${ }^{4}$ If several (simple or eomplex) tess compose in phanse or a clause (as, e.g., AntiMagn and $S_{0}$ compose minot injury), we separate these th's by at 'o' sign. For the theoretical harkground and further details of how this can be compesed with each other, see the literature on Meaning 'l'ext Theory; e.g., (Mel'cuk and Polguère, 1987).
}

LF. Moreover, the existence of $L_{1} \wedge L_{1} F_{2}$ in a language does not moan that w $2 \wedge \mathrm{LW}_{1}$ is also available. 'Therefore, in Le sequences, one argument, is the 'hub' - the point of departure (or the expanded to and the other argunent is the 'hub expander'. How an specilic LF can be expanded, i.e. which br secpences are possible, depends individually on this LF, and on which tess are further available for the entity the ress are applied to. Compare, e.g., the ra secuences that instantiate the negated antonymy reiteration for $V_{0}$ (foryelting) and the two, which instiantiate the same relation for $V_{0}($ lie) :

Forgetting (the $V_{0}$ clanse is in all examples realized as I forgot; to abloreviate, we write '...' instead):

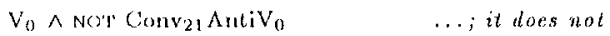

$$
\begin{aligned}
& V_{0} \wedge(\text { Magn o) NO'I Antivo Primind me of anything } \\
& \text { Vol think of it (now). } \\
& V_{0} \wedge\left(\text { Magn of linOperr } \circ \text { Antis } S_{0} \quad \ldots,\right. \text { it (totally) } \\
& V_{0} \wedge\left(M a u^{\circ}\right) \text { has slipped my mind. } \\
& \text { Lio ('...' stands hore for } / 10 \text { is lying): } \\
& V_{0} \wedge N O T \text { Opter } 0 S_{0} A n t i V_{0} \quad \ldots ;(\text { simply) does not } \\
& V_{0} \wedge\left(\text { iencer } V_{0} \text { o Nes'l Anti } \Lambda_{0} \quad \ldots\right. \text {. } \\
& \text { what he says is not true. }
\end{aligned}
$$

Apart from the reiteration or collocalion relation it stands for, an t.F sequence is further characterized by its possible syutactic realizalions and its functional content.

\subsection{Syntactic Realizations of LIF $\mathrm{Sc}$ quences}

As a rule, an bi sequence is realizable by several different syntactic constructions. Ilow these constructions can look like is predetermined by each t, sequence individually (and by the inlormation to be communicated). For example, Oper, $\wedge$ Oper, (more precisely, strict repetition) is in general realizable only as a paralaclic comples clanse; of. Hane a look al it; please hane a look. In contrast, for example, Oper, $\wedge$ Magun o $S_{0}$ is realizable $\cdots$ when applied to, e.g., drcision-by all syutactic constructions possible, ef:

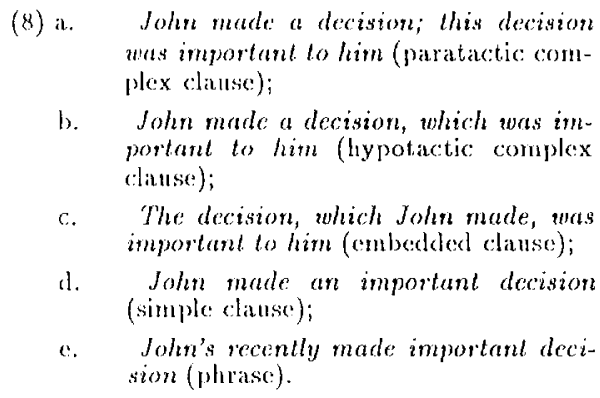

"The relevance of syntactic varialions for the realizaltion of discourse structure relations is well known, $\mathrm{f}$, e.g., (llovy, 1993). 


\subsection{Functional Content of LF Se- quences}

Semantics, lexis, and syntax of LF sequences do not provide sufficient criteria for the choice of one sequence over all other comparable ones. These criteria must be provided by the functional content we associate with each sequence (or reiteration and collocation relation, respectively). The functional content of the reiteration and collocation relations listed in Table 1 is presented in Table 2.5

\begin{tabular}{|ll|}
\hline strict repetition & insisting restatement \\
\hline synonymy & clarifying restatement \\
\hline superordination & $\begin{array}{l}\text { generalizing restatement, } \\
\text { clarifying restatement, } \\
\text { class-referencing }\end{array}$ \\
\hline $\begin{array}{l}\text { metaphor. } \\
\text { repetition }\end{array}$ & $\begin{array}{l}\text { pictoresque restatement, } \\
\text { intensifying restatement }\end{array}$ \\
\hline negated antonymy & contrastive restatement \\
\hline conversion & $\begin{array}{l}\text { clarifying restatement, } \\
\text { constituent enhancement, } \\
\text { pespective slifting }\end{array}$ \\
\hline process-actor & $\begin{array}{l}\text { identification, } \\
\text { actor-introduction }\end{array}$ \\
\hline cause-process & $\begin{array}{l}\text { processual enhancenent, } \\
\text { causal enlancement, } \\
\text { causer introduction }\end{array}$ \\
\hline initialization- process & $\begin{array}{l}\text { processual extension, } \\
\text { beginning extension }\end{array}$ \\
\hline attribution & attributive refinement \\
\hline manifestation & $\begin{array}{l}\text { predicative refinement } \\
\text { manifestation enlancement }\end{array}$ \\
\hline
\end{tabular}

Table 2: Functional content of some reiteration and collocation relations

\section{TOWARDS LEXICALLY BIASED DISCOURSE RELATIONS}

Due to their functional content, wF sequences serve as instantiations of individual discourse structure relations. In our work, we suggest that these individual discourse structure relations can be organized collerently in terms of the functions and semantic distinctions they represent. In accordance with the claim that the availability of specific t.F sequences is dependent on the cntities the LFs are applied to, we further suggest that this organization must be done individually for each predicative entity (cf. Wanner, 1994).

Based on this, we define taxonomies (one for each predicative entity) which have been inspired by Halliday's proposal for grouping interclansal logicosemantic relations (cf. Ialliday, 1985). Ilow such an organization can be realized efficiently using inheritance techniques is described in (Wanner, 1992).

\footnotetext{
${ }^{5} 7$ his is not to say that these functions are the only ones that are possible
}

Although our model is not restricted to interclausal relations, two features of Ilalliday's proposal are valuable to us: (i) that a logico-semantic relation 'expands' one wording by an another one rather than connecting two given wordings and (ii) that a logico-semantic relation can be further decomposed with respect to its: 1. semantics, 2. syntactic realization, 3 . communicative structure, and 4. with respect to the speaker's intention, which molivates the selection of this relation during the text production process.

In what follows, we discuss first the general taxonomy of our 'expanding' discourse structure relations for processes and then the decomposition of the relations along these four dimensions. Following the conventions in RsT, we call the expanded part 'nucleus' and the expanding one 'satellite'.

\subsection{Taxonomy of Lexical Discourse Re- lations}

A taxonomy of lexical discourse structure relations is to be understood as a hierarchy of alternative choices of increasingly delicate relations. 'The most delicate relations are LF sequences represented by their functional content. The top level of the taxonony represents, thus, the most global types of expansion. In accordance with (Ialliday, 1985), these are ErsmoRATION, EX'TENSION, and INIIANCRMENT' RLABORATION subsumes all those expansions which ensure a deeper understanding of the meaning communicated by the nucleus wording. $\Lambda$ deeper understanding of the nucleus wording is ensured by restating, refining, or clarifying it (the next level of BHAORN'TON in the taxonomy). For example, all reiteration relations are of the ELABORATION type.

The ExTension expansions extend the meaning communicated by the nuclens worling. This can be done by introducing a new constituent that is related to what has been said in the nuclens, by adding a new action of the known constituents, elc. Beginning extension is, c.g., an EXTENSION.

The ENIIANCIMANT expansions qualify the meaning communicated by the nucleus wording by adding a reference of causation, time, location, manner, mode, etc. An example of ENIIANCEMENT is causal enhancement.

Figure 1 shows in more detail the Fis BORATION fragment of the taxonony in network form. According to this figure, RESTATEMENT can be realized as a contrastive, a generalized, or as a repeating restatement, respectively. As shown in Table 2, CONTRASTIVE RES'ATEMENT corresponds to the reiteration negated antonymy, GENEIRAJIZING RESTATEMENT to superordination, respectively. REPRA'TING RESTATEMENT is further insisting, clarifying, illustrative, pictoresque, etc. (sce again Thble 2 for corresponding reiteration relations). 


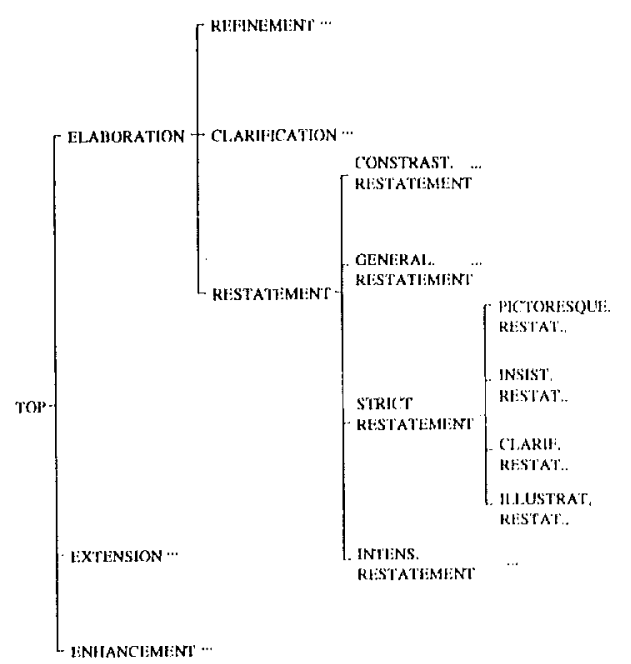

Figure 1: A fragment of a lexical discourse structure relation taxonomy

\subsection{Decomposition of Lexical Dis- course Structure Relations}

As presented in Figure 1, the relations are still too global to be useful for lexical choice. Consider, eg. A'TRRIBUTION - a subtype of the RLINIMMSN'T relation; it allows for varions decompositions with respect to all four dimensions mentioned alove:

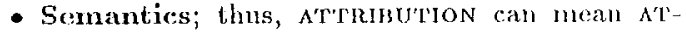
Trubutron, e.g., of a process, of one of the participants of this process, or of one of the circumstances of this process; if A'T'TRBBUTION of a participant (let's say the $\Lambda C^{\prime} \mathrm{C} O \mathrm{R}$ ) is meant, it is still undetermined what kind of attribution this is (e.g., a one which enables the actor to engage in the process, a one which prevents him from engaging in this process, etc.).

- Syntactic realization; how the varions AT'R BUTYONs can be realized syntactically depends on the semantic and lexical properties of the information to be communicated. For example, Monica flew to Ilaly; it was a very pleasant journey is also realizable as a subordinated clause (Monica flew to Italy, which was very pleasant); as a simple clause (Monica lad a very pleasant journey to Italy); and as a phrase (Monica's pleasanl journey to Italy).

- Communicative structure; the communicative structure of at'rrubutron varies depending on the order in which nucleus and satellite are realized. Cf., e.g.: Monica Jlew to Haly; it was a very pleasant journey vs. It was very pleasant, Monica's journey to Ilaly.

- Speaker's intention; selecting the A'T'RnuTION relation the speaker is assumed to intend,
(R1/CONSEQUENCE

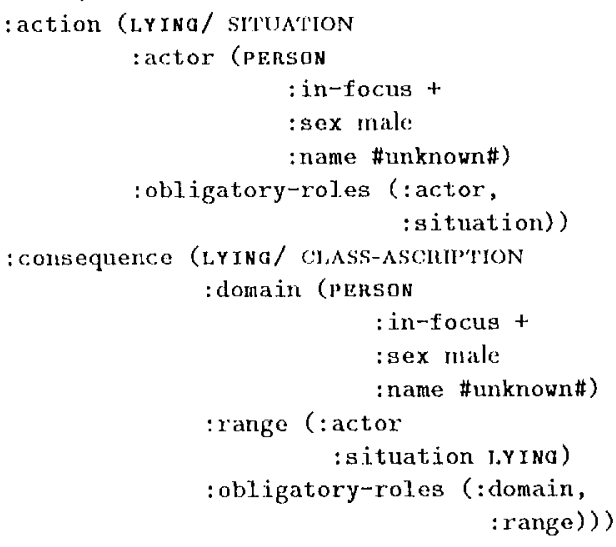

ligure 2: 'The text, plan for the text with the meaning "The man is Jying; the consequence of this is that this man is a liar

e.g., a justification of what las been communicated in the molens as in John failed the exam; it was very difficull; a consequence of it John has been shot - - he ist dead, etc.

The increasingly delicate specifieations achieved by decomposition are also represented hierarchically in network form; one network for each dimension.

\section{GETTING THE RELATIONS AC- CROSS}

The lexical choice process, which makes use of the discussed discourse structure relation taxonomies, and the representation of lexical resources are described in detail in (Wanner, 1992, 1994). Mere we focus on the interface between the first level text planning and the lexical choice module; and on the output as produced by the lexical choice module.

'The computational franework in which our model lais partially been implemented, is the systemic text generator Kowe (latemin el al, 1991). One sonres of constraints lor the first level text orgintizalion comes in Komber from an mest-based planner. "The ontput of this planner is a collection of case frames with $\mathrm{RS}^{\prime} \mathrm{l}$ relations holding between them as shown in Figure 2.

Starting from a text plan of this kind, the lexical choice molule traverses a multilayered collection of networks (one of these layers is given by a taxonomy ol lexical discourse stmeture relations discussed). During the tritversal, the text plan is transformed into it lexicalized Partial Cirammatical Struclure (PCS) ${ }^{7}$ it is called 'partial' because it contains precisely that amount of grammatical information which is necessary

\footnotetext{
"IRecent developments of this planner are descrilsed in (Hovy et al., 1092).

${ }^{7} \mathrm{~A}$ pas corresponds, roughly speraing, to the Parlial surface functional Description (ISPD) specilication in the COMEl systemn (Mckeown el al., 1900).
} 


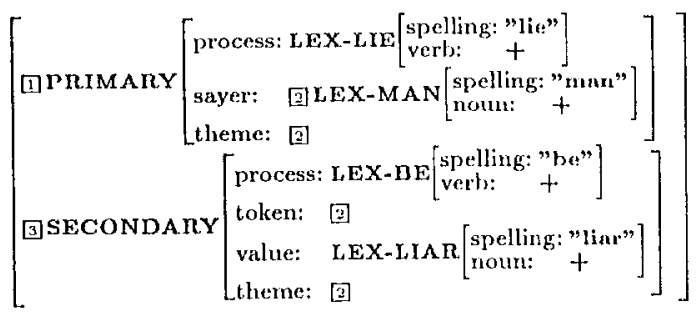

Figure 3: PGS structure for the sentence The man is lying; he is a liar

for lexical choice. The PGS is passed to the grammar (a systemic grammar of German; cf. Teich, 1992) for final syntactic realization. Figure 3 shows a sample PGS encoded as a Typed Features Structure (cf. Bateman et al., 1992).

The first and the most important task in tailoring the text plan to linguistic resources is to find a lexically biased discourse structure relation for the RST relation specified in the text plan. The search is done in accordance with the functional content, the intention of the speaker, and the contents of the arguments of the RST relation. If the $\mathrm{RS} \mathrm{T}$ relation connects unrelated case frames ${ }^{8}$ (as, c.g., EVIDlince in In winter, the days are short. It is getting light late and early dark.) these case frames are realized independently without being connected by a lexical discourse structure relation. If the case frames are related, the following three variations are possible:

(i) An RST relation instantiation coincides with a lexical discourse structure relation; as, e.g, the instantiation of RESTATEMENT in the following rudimentary text plan coinsides with our RESTATEMENT:

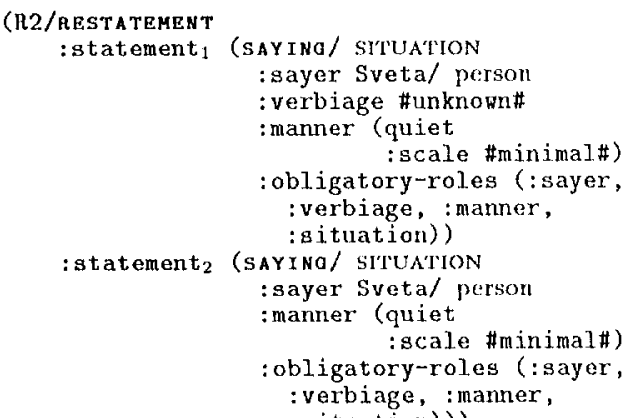

If so, the subclassification of the lexical discourse structure relation determines its final realization. For example, the above text plan could be realized as a Generalizen Rlstatemman: Svela flüsterle; sio sagte etwas ganz leise lit. 'Sveta whispered; sho said something very quietly'; an INTENSIFYING RESTATRMEN'T: Sveta sagte elwas sehr leise; sie hatchle es kaum hörbar hin lit. 'Sveta said something very quietly; she breatlied it lardly audible', etc.

(ii) An RST relation instantiation subsumes several dis-

\footnotetext{
${ }^{8}$ Case frames are considered to be unrelated if between them or one of their roles no identity, is-a, causer, location, etc. relation holds.
}

tinct classes of lexical discourse structure relations; as, e.g., the instantiation of the RST relation CONTRAST in (this plan is also highly simplified):

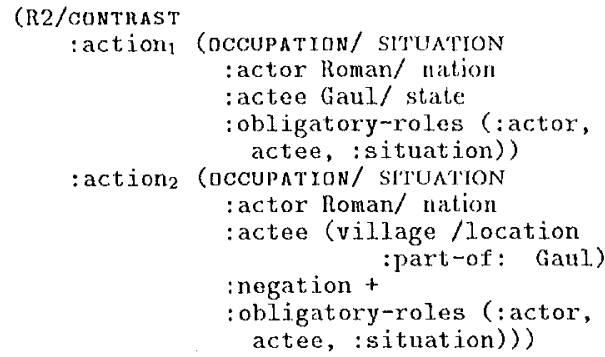

may be realized either as CONTRASTIVE CLARIFICATION (9a) or as CONTRASTIVE GNIIANCEMENT (9b):

$$
\begin{aligned}
& \text { (9) a. Gaul is entirely occupied by the Ro- } \\
& \text { mans; well, not enlirely ... one small } \\
& \text { village still holds out. } \\
& \text { b. Gaul is almost entirely occupied by } \\
& \text { the Romans; but one small village still } \\
& \text { holds out. }
\end{aligned}
$$

In this case, the taxonomy of lexical discourse structure relations is entered at a relatively general level (in the worst case at TOP).

(iii) An Rs' relation is not captured by our taxonomy (as, e.g., CONCBssion). Then, the corresponding case frames are treated as unrclated (see above).

\section{RELATED WORK}

Onr proposal for the description of lexically biased discourse structure relations resembles Danlos' work (Danlos, 1987), who presented acceptable clause pattern sequences explicitly in a Discourse Crammar. The basic difference between Danlos' work and ours is that in the Discourse Grammar, clause patitern sequences are represented as concrete valency schemati while in our model they are represented as functional distinctions that encode sequences of Irs. As a result, we do not face the problem of being restricted to a concrete small domain as Danlos does.

Meteer's text planner (Meteer, 1992) is another proposal for the realization of lexically biased cliscourse stucture relations. But, while we argue that lexically biased discourse structure relations are to be realized by a functionally motivated lexical choice model, Meteer sugrgrests a single structurally motivated model for text. planning, which also subsumes lexical choice. 'This is different from, eg. (Rubinoff, 1992), who ensures the expressibility of discourse structure relations provided by a conventional text; planner by annotating linguistic structures.

Elhadad's proposal (Ellandad, 1992) to use 'lopot (inference rules that encode relations between propositions incorporating lexical material) as discourse structure relations is aimed at exploiting lexical phenomena for discourse organization. Whadad focuses, however, on the 'argumentative potential' of lexical items rather than on lexically biased discourse structure relations. 


\section{CONCLUSIONS AND FUTURE WORK}

In this paper, we argued that it is useful to distinguish between two levels of discourse organization: a global discourse organization, which is not aflected by linguistic means; and a finer discourse organization, which is built up in accordance with the linguistic material that is available for the meaning communicated.

We have shown that reiteration and collocation relations may function as discourse structure relations and that these relations are well represented by Lexical Function sequences. We presented a taxonomy of lexically biased discourse structure relations, which is related to Ilalliday's proposal for grouping interclausal logico-semantic relations and snggested to use this taxonomy in a lexical choice module.

One of the open problems we face is how sulficiently detailed contextual constraints can be acquired in order to guide the choice of one discourse structure relation over others. 'This will certainly be one of the topics we will have to address in the future.

\section{ACKNOWLEDGEMENTS}

This work has been carried out while the anthor was affiliated with the Inlegrated Pullication and Information Systems Institute of the (iMD, Darmstiudt. Many thanks are due to John Mateman, Lidija Iordanskaja, and Igor Mel'čuk for valuable comments on an earlier draft of this paper.

\section{References}

Bateman, J. A. et al. (1991). 'Powarsls an Architecture for Situated 'Text Generation. In ICCICL, Penang, Malaysia. Bateman, J. A. et al. (1992). The Nondirectional Representation of Systemic Functional Grammars and Semantics as Typed Feature Structures. In Procedings of COLING-92, volume III, pages $916 \ldots 920$.

Dale, R. (1989). Generating Referring Lipressions in a

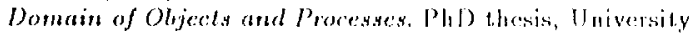
of Edinburgh.

Danlos, L. (1987). The Linguistic Basis of Trat Generation. Cambridge: Cambridge Iniversity Press.

Elhadad, M. (1992). Generating Colierent Argunentalive: Paragraphs. In I'roceedings of COLING '?2, volume II, pages $638-644$.

Grosz, B. J. and L. Sidner (1986). Attention, Intentions and the Structure of Disconrse. In Computational linguistics Journal, 12(3):175-2014.

II alliday, M. A. K. and R. Hasan (1976). Cohesion in English. London: Longman.

Ilalliday, M. A. K. (1985). An Introduction to finctional Grammar. I.ondon: Edward Arnold.

IIovy, F. II. (1993). Automated Discourse Generation Using Disconrse Structure Relations. In Artificial Intelligence, 63(1-2):341--386.

llovy, E. et al. (1992). Fimploying Knowledge Resources in a New 'lext Planner Architecture. In Proceedings of the 6th. Natural Language Generation Workshop, 'Trento, Italy.
Iordanskaja, h. N. et al. (1991). Texical Selection and Paraphrase in a Meaning-l'ext Generation Model. In C. I. Paris et al. (editors), Natural Language Generation in Artificial Intclligence and Computational Linguistics. Dordrecht: Kluwer Academic: Publishers.

Mann, W. C. and S. A. Thompson (1987)

Rhetorical Structure 'Theory: $\Lambda$ Theory of Text Orgatization. In L. Polanyi (editor), The Structure of Discourse. Norwood, New Jersey: Mblex Publishing Corporation.

McCoy, K. F. (1989). Generating Context Sensitive Responses to Object-related Misconceptions. In Artificial Intelligence, 41:157 195.

McKeowII, K. R. and W. R. Swartout (1987).

Langnage Generation and Explanation. In Annual Reviews in Compuler Science.

McKeown, K. R., ct al. (1991). Natural Janguage Ceneration in COMl:T. In R. Dale, el al. (cditors), Current Reserarch in Natural Langunge Generation. Iondon: Acatdemic: Press.

Mckeown, K. R. (1985). Text Generation: Using Dis. course Strateqies and locus Constraints to Generate Natural Language Text. Cambridge: Cambridge University Press.

Mel'énk, I. $\Lambda$ and $\Lambda$. Polgnère (1987). A Formal lexicon in the Meaning- Text theory (or llow to Do Lexica with Worls). In Compulationnl Linguistics, 13(3-4):276-289.

Metcer, M. W. (1992). Lixpressibility and the Problem of Efficient Teat Planning. London: P'inter Publishers.

Reiter, li. (1991). A New Model of Lexical Choice for Nouns. Tn Compulalional Inlelligence, 7(1).

Rubinolf, R. (1992). Integrating Textplanning and linguistic: Choice by Annotaling linguistic Structures. In Procedings of the 6th. Natural Language Cieneration Workshop, 'Trento, Italy.

Teicle, R. (1992). Komet: Cirammar Docnmentation. Technical report, GMI)/Institnt für Integrierte P'ublikations- und Informationssysteme, Dirmstidt, Germany.

Tutin, A. and R. Kittredge (1992). Lexical Choice in Context: Cencrating Procedural lexts. In Proceedings of COIING '?2, volume II, pages $763-769$.

Wanner, I. and I. $\Lambda$. Bateman (1990). Lexical Conccurrence Relations in l'ext. Cencration. In I'rocedings of the 5th. Nalural Langutge Cieneration Workshop, Dawsoll, P^.

Wanner, L. (1992). Lexical Choice and the Organtzation of Lexical Resources in 'Text Generation. In Proceedings of the Luropent Conference on Artificial Intelligence, $\mathrm{Vi}$ cma, Austria.

Wanner, L. (1994). Building Another Bridge over the Generation Gap. In Procedings of the 7th. Natural Langunge Generation Workshop, Kennebunkport, Maine. 

Parsing 
